\title{
O TESTEMUNHO DOS ARQUIVOS E O TRABALHO DO HISTORIADOR DA EDUCAÇÃO'
}

DOI: http://dx.doi.org/10.1590/2236-3459/75047

\author{
Juarez José Tuchinski dos Anjos' \\ 'Universidade de Brasília (UnB), Brasília/DF, Brasil
}

$\cos 8$

\begin{abstract}
Resumo
Tomando o arquivo como um lugar físico e epistemológico, o objetivo é refletir sobre o que ele pode testemunhar para o trabalho do historiador da educação. Dialogando com a historiografia sobre o papel dos arquivos na escrita da História, num primeiro momento reflete-se sobre as relações entre Arquivo, Memória e História. Em seguida, discutem-se seus dois diferentes níveis de testemunho para a pesquisa históricoeducacional: o testemunho intencional e o não intencional sobre a educação.

Palavras-chave: arquivos, historiografia, história da educação.
\end{abstract}

\section{EL TESTIMONIO DE LOS ARCHIVOS Y EL TRABAJO DEL HISTORIADOR DE LA EDUCACIÓN}

\section{Resumen}

Tomando el archivo como un lugar físico y epistemológico, el objetivo es reflexionar sobre lo que él puede testimoniar para el trabajo del historiador de la educación. Dialogando con la historiografía sobre el papel de los archivos en la escritura de la historia, en un primer momento se refleja sobre las relaciones entre Archivo, Memoria e Historia. A continuación, se discuten sus dos diferentes niveles de testimonio para la investigación histórico-educativa: el testimonio intencional y el no intencional sobre la educación.

Palabras clave: archivos, historiografía, historia de la educación.

\section{THE EVIDENCE OF ARCHIVES AND THE WORK OF HISTORIANS OF EDUCATION}

\begin{abstract}
Taking the archive as a physical and epistemological space, this study aims at a reflection on what it may evidence to the work of historians of education. Dialoguing with the historiography on the role of the archives in the writing of History, the first part reflects on the relations between Archive, Memory, and History. Then its two levels of evidence are discussed for the historical-educational research: intentional and unintentional

${ }^{1}$ Este artigo apresenta resultados parciais do projeto de pesquisa "Os Arquivos de Brasília e a História da Educação Brasileira no Império: inventário de fontes e perspectivas de pesquisa", que conta com financiamento da Fundação de Amparo à Pesquisa do Distrito Federal, agência de fomento à qual registro agradecimentos.
\end{abstract}


evidence on education.

Keywords: archives, historiography, history of education.

\section{LE TÉMOIGNAGE DES ARCHIVES ET LE TRAVAIL DE L'HISTORIEN DE L'ÉDUCATION}

\section{Résumé}

En prenant le archive comme un lieu physique et épistémologique, l'objectif est de réfléchir à ce qu'il peut témoigner pour le travail de l'historien de l'éducation. En dialoguant avec l'historiographie sur le rôle des archives dans l'écriture de l'histoire, au début, il réfléchit sur la relation entre les archives, la mémoire et I'histoire. Puis, se discute ses deux different niveaux de témoignage à la recherche historique-educative: le témoignage intentionnel et non intentionnel sur l'éducation.

Mots-clés: archives, historiographie, histoire de l'éducation. 
unto com a renovação experimentada pela pesquisa em História da Educação no Brasil nas últimas décadas², pode-se afirmar que houve, também, outra de igual monta: a renovação da identidade dos historiadores e historiadoras da educação. De educadores historiógrafos e interessados no passado educacional do país por razões as mais diversas (desde políticas reformistas até aquelas ligadas à sala de aula e à formação de professores), têm se constituído, cada vez mais, em comunidade de historiadores e historiadoras no sentido estrito do termo: especialistas na produção do conhecimento histórico educacional, guiando-se pelas regras e elementos basilares daquilo que Marc Bloch tão bem definiu como O Ofício do Historiador. (BLOCH, 2011).

Ora, todo historiador ou historiadora da educação, em algum momento, visitou ou visitará aquele que é o lugar a partir do qual muitas de suas pesquisas são escritas: o Arquivo. Tal relação, no ofício, é tão intrínseca e inevitável a ponto de Georges Duby não ter hesitado, certa vez, em afirmar: "Ninguém pode chamar-se historiador se não passou parte de sua vida explorando um depósito de arquivos". (DUBY, 1994, p. 3, tradução livre). Entretanto, como nota Marlon Salomon,

Nos últimos anos a reflexão teórica sobre a escrita da História vem sendo circunscrita a um domínio que muitas vezes menospreza os arquivos e opõe frequentemente a reflexão sobre a arquitetura das ideias à pesquisa e exatidão do arquivo [...]. O problema é que o discurso metodológico e o discurso teórico da história pressupõem os arquivos como dados e evitam a todo custo uma reflexão sobre sua construção e sua produção. [Todavia] nossa atualidade nos faz ver que os arquivos não estão dados e, ao mesmo tempo, problematiza todo discurso apriorístico que os pressupõem. (SALOMON, 2011, p. 14).

Como expõe Salomon, se vemos crescer entre os historiadores o interesse pela história da historiografia como mecanismo de crítica e elucidação da produção, pouco se tem investido, segundo ele, na dimensão teórica que antecede a própria escrita da História e que passa, inevitavelmente, pela problemática da relação do pesquisador com os arquivos. É verdade que, no campo da história da educação, já foram empreendidas substanciais reflexões sobre essa questão ${ }^{3}$. Mas nem por isso as considerações de Salomon deixam de ser provocadoras para nós, sobretudo, porque o risco de nos convencermos de que já estamos vacinados contra aquilo que Etienne François (1998) chamou de "miragem dos arquivos" sempre está a nos espreitar e o único antídoto possível contra esse mal é o de procedermos, continuamente, à problematização e teorização dessa relação.

É dentro do quadro acima delineado, que emerge o objetivo deste artigo: refletir sobre o que podem testemunhar os arquivos para o trabalho do historiador da educação. $A$ hipótese em tela é de que, do Arquivo, por conta das operações de memória que o produzem, emerge um duplo testemunho para esse trabalho de escrita da história da educação. De uma parte, um testemunho intencional sobre ela, nascido da vontade de lembrar e fazer lembrar os compromissos dos produtores/gestores do arquivo para com a

\footnotetext{
2 Vejam-se, a esse respeito, as recentes análises de Bastos (2016) e Buffa (2016) bem como as mais antigas, realizadas no início dos anos 2000, como as de Catani e Faria Filho (2002), Marta Maria Chagas de Carvalho (2003) e Faria Filho e Vidal (2005).

${ }^{3}$ Conferir, dentre outras, as empreendidas por Clarice Nunes (1990), Clarice Nunes e Marta Carvalho (1993) e Maria Lúcia Hilsdorf (1999).
} 
educação, geralmente, em sua forma escolarizada; de outra, um testemunho não intencional, que permite observar, apesar da força da memória, as contradições da relação desses agentes com a educação e seus sujeitos, tanto na sua forma escolarizada como no confronto desta com outros modos de socialização das gerações mais jovens na História.

Antes de prosseguir, no entanto, convém evidenciar algumas premissas teóricas, metodológicas e cronológicas que estou adotando para a condução desta reflexão.

Em função de meus interesses de pesquisa atuais, estou entendendo o Arquivo como o lugar físico que abriga os documentos de que se valerá o historiador ou historiadora da educação na construção de suas explicações sobre os homens e mulheres do passado. Esse entendimento abarca, assim, não só os arquivos públicos ou institucionais - como os arquivos nacionais, estaduais e municipais - como também bibliotecas públicas e institucionais, nas quais repousa documentação impressa, geralmente custodiada na chamada Seção de Obras Raras ${ }^{4}$. Essa demarcação agrega, ainda, um segundo sentido ao que estou entendendo por Arquivo: um sentido epistemológico. De fato, o arquivo, mais do que um lugar físico ou lugar de memória, naquela clássica definição de Pierre Nora (1993) é, para o historiador, um lugar epistêmico, a partir do qual e no embate com o qual ele se questiona (ou deveria sempre se questionar!) sobre a possibilidade ou impossibilidade de se construir determinado conhecimento sobre diferentes passados que, se não repousam inteiros e prontos nos arquivos - bem lembra-nos Arlette Farge (2009) no seu insuperável trabalho - não pode prescindir dele para sua produção, sob o risco de, perante o tribunal disciplinar da História, de que falou E. P. Thompson (2009), seu discurso tornar-se inválido e/ou fictício.

Já por educação - o fenômeno histórico que, de maneira geral, buscamos identificar a partir das caixas e papéis do arquivo ou impressos e obras raras de uma biblioteca - quero referir-me tanto à educação escolarizada quanto à educação não escolar, concordando, assim, com Eliane Marta Lopes e Ana Maria de Oliveira Galvão quando escrevem:

a educação nunca se restringiu à escola. Práticas educativas ocorrem também fora dessa instituição, às vezes com maior força do que se considera. A cidade, o trabalho, o lazer, os movimentos sociais, a família e as igrejas tinham - e continuam tendo - um enorme poder de inserir as pessoas em mundos culturais específicos. (LOPES; GALVÃO, 2010, p. 19).

Em termos metodológicos, dialogarei com análises empreendidas por historiadores brasileiros e de outros países, buscando evidenciar as consequências que algumas de suas observações acarretam quando cotejadas com especificidades da pesquisa em história da educação e do tipo de conhecimento que, nas incursões pelos arquivos, o historiador ou historiadora da educação espera chegar a elaborar.

\footnotetext{
${ }^{4}$ Em contrapartida, embora não ignore os arquivos escolares, centros de memória ou arquivos pessoais como Arquivos igualmente relevantes para a pesquisa em história da educação, os excluo (ao menos em suas especificidades) do horizonte de análise deste texto, por não estar, atualmente, em contato com eles nas pesquisas que me instigam à produção do presente ensaio. Contudo, é possível que alguns aspectos aqui abordados, a critério do leitor, possam ser empregados também na teorização desse tipo de arquivo. Para uma análise específica deles, remeto, dentre outros, ao estudo de Maria João Mogarro (2005) sobre os arquivos escolares, aos artigos reunidos no dossiê sobre Centros de Memória, organizado por Maria Angela Borges Salvadori e Maurilane Biccas (2005) e a pesquisa de Maria Teresa Santos Cunha (2008), sobre arquivos pessoais.
} 
Relativamente à cronologia, o arquivo - lugar físico e epistemológico de que me ocupo neste texto - é aquele que contêm evidências documentais sobre a educação no "longo século 19" (HOBSBAWM, 2015), isto é, de fins do século 18 - época em que, no ocidente, vemos nascer uma escola pública estatal, inicialmente em Portugal depois em outros países (VEIGA, 2008) - até o início do século 20, momento de início da expansão/consolidação do modelo de educação escolar, após sua importante fase de produção como "tradição inventada" (HOBSBAWM; RANGER, 1988) durante o Oitocentos. Em que pese tal cronologia, é possível, não obstante, que parte dessas reflexões também se revelem pertinentes, a critério do leitor, para pensar os arquivos e seus testemunhos em outros momentos significativos da história da educação.

$\mathrm{O}$ artigo divide-se em duas partes. Na primeira, discutirei brevemente as relações entre Arquivo, Memória e História. Em seguida, investirei na reflexão sobre os dois diferentes níveis de testemunho dos arquivos para a pesquisa histórico-educacional: o testemunho intencional sobre a educação e o não intencional. Ao final, encerro com algumas considerações.

\section{Arquivo, memória e história}

Ao adentrar no espaço físico de um arquivo, somos tocados das mais diversas formas: pelo odor das luvas com as quais vamos manusear os documentos ou obras raras, pela iluminação intensa da sala de consultas, pelo cheiro característico do papel que serve de suporte às informações que esperamos levantar, pela fragilidade do material ou, surpreendentemente, pelo notável estado de boa conservação em que às vezes se encontra.

Mas, também somos tocados - quando não atravessados - pela decepção de não encontrar algo que, em princípio acreditávamos, deveria estar lá, por sabermos, seja através das pesquisas dos pares ou de outros documentos já localizados, que esse "algo" existiu no passado que buscamos compreender. Ou ainda, de encontrarmos apenas parcela do que fomos coletar, constatando que o seu "resto", muitas vezes a parte mais importante e relevante para a elaboração de uma explicação histórica, já não pode ser localizado!

Se num primeiro instante a relação do historiador com os arquivos é sensorial, a partir de certo momento ela passa a ser epistêmica e, superada a alegria ou decepção por achar ou não encontrar, chega a hora de acaroar a si e ao arquivo a fim de tomar tais experiências como um bom ponto de partida para o início daquilo que Michel de Certeau (2002) vai designar de operação historiográfica. É a ocasião de o historiador interrogar-se sobre as forças que agem e produzem, antes dele, o arquivo. É o momento de dialogar com a deusa e mãe das Musas, Mnemosine, que para os gregos e para nós, personifica a memória.

Antes de tudo, a memória, essa interlocutora que media o encontro do historiador com o Arquivo não é, ela própria, um dado, mas antes uma construção social, feita de lembranças e esquecimentos, registra Peter Burke (2000). E mais: tal construção, de modo algum é espontânea, mas ação deliberada, pois como assevera Ulpiano Meneses ela 
é um processo permanente de construção e reconstrução, um trabalho como aponta Eclea Bosi. O esforço ingente com que costumam investir grupos e sociedades, para fixá-la e assegurar-lhe estabilidade é, por si só, indício de seu caráter fluído e mutável. (MENESES, 1992, p. 10).

Nesse ponto, o historiador há que indagar-se sobre quais, para falar com Halbwachs (2002), são os grupos que produzem essa memória coletiva, relativa aos fenômenos que deseja investigar a partir do arquivo. Em se tratando do Brasil, o mais recorrente é que os arquivos que frequentamos estejam ou nas mãos dos agentes do Estado nas suas diversas esferas de atuação ou, então, de instituições em maior ou menor medida a ele alinhadas que, pelas mais variadas razões, sentiram em determinado momento de suas trajetórias, a necessidade de produzir a memória. Mas, tanto num como noutro caso, essa memória - e de novo o diálogo com Ulpiano Bezerra é fundamental por aquilo que nos lembra - "não é espontânea: para manter-se precisa permanentemente ser reavivada". (MENESES, 1992, p. 15). É por essa razão que um dos lugares mais significativos para o reavivamento das memórias dos grupos que as produzem é, sem dúvida, o próprio espaço arquivístico. Destarte, para prosseguir no enfrentamento da relação arquivo, memória e história, compete ao historiador considerar seriamente os possíveis interesses que levaram não só a produção da memória como do espaço arquivístico como um de seus signos. É preciso tomar como problema a função social do Arquivo.

No caso da relação entre memória e arquivos estatais, as considerações de Gustaaf Janssens (2010) são bastante esclarecedoras. Para ele,

a função social do arquivo se reflete tanto no presente quanto no passado. $O$ arquivo não só determina em que medida o governo deve prestar contas ao cidadão, mas também o conteúdo e a orientação da memória coletiva e da identidade (nacional) de uma comunidade. (JANSSENS, 2010, p. 83, tradução livre).

Já no caso dos arquivos das instituições, o que parece muitas vezes estar em jogo é o controle da memória institucional, do que e quem será lembrado, num processo em que, como faz Michelle Perrot (2005), é acertado conceber a "constituição do arquivo [...] [enquanto] o resultado de uma sedimentação seletiva produzida pelas relações de força e pelos sistemas de valor". (PERROT, 2005, p. 14). Se ao adentrar no arquivo os documentos repousam no silêncio e na tranquilidade, o esforço social de memória, manifestado nas decisões que os trouxeram até ali, não pode ser ignorado pelo historiador.

Edward Carr (2006), em famoso estudo, enfatizou que antes de ler um livro de história, deveríamos informar-nos sobre seu autor. No caso do arquivo, parece que essa premissa também é verdadeira, já que saber de antemão quem o constituiu e em que condições isso se deu, pode ajudar a compreender melhor o que se acha e o que se oculta na documentação que se tem em mãos. Mas, para além dessa comparação, não se pode ignorar que mesmo havendo um gesto decidido de produção de uma memória social por parte de determinados atores no momento originário de um arquivo há, ainda, o poder de acesso à documentação custodiada, no qual, muitas vezes, interesses distintos daqueles que, por primeiro, produziram a memória estatal ou institucional materializada, podem, no presente do historiador, fracionar tal memória, pelo que decidem tornar acessível ou não a cada consulente. Quem de nós já não vivenciou a experiência de ir a um arquivo e perceber que determinada política arquivística adotada ou, até mesmo, a boa relação com os 
arquivistas foi decisiva para achar (ou não) determinado documento ou determinado instrumento de pesquisa para o acesso a uma fonte? Afinal, como já observaram Clarice Nunes e Marta Carvalho (1993), mediando o encontro do historiador com o mundo documental e a memória, estão os seus organizadores, os arquivistas, cujo poder "se radica particularmente nas prioridades e mecanismos institucionais de acolhimento, preservação e/ou restauração, classificação e/ou identificação dos conteúdos e estabelecimento das condições de acesso à documentação sob sua guarda". (NUNES; CARVALHO, 1993, p. 24).

Sabendo e levando na devida conta toda essa gama de questões que, embora nem sempre claras, rondam o historiador enquanto se senta confortavelmente à mesa de consulta para ler e extrair dados dos documentos na sala do Arquivo, como é que ele parte da memória que produziu o acervo e das relações do poder que o tornam acessível ou não, para a História que intenta produzir a partir dele? Se historiadores como Jacques Le Goff (1990) são unânimes em afirmar que para tanto é preciso submeter a memória à História, como é que se pode, efetivamente, realizar isso quando é, justamente de um lugar embebido de memória e relações de poder que teremos de partir em busca da cientificidade da escrita da História?

Certamente, muito do próprio caminho da pesquisa vai, aos poucos, ajudando o historiador - ainda que exigindo-Ihe inúmeros daqueles recomeços sobre os quais escreveu Lucien Febvre (1989) num de seus combates - a ir dominando a memória e extraindo dela o melhor do material e da essência de vida a partir da qual formulará suas interpretações sobre o que era ser homem, mulher, criança, professor ou professora, pai ou mãe num determinado passado. Mas um olhar crítico acerca das marcas da memória sobre o Arquivo e o modo como ela, em diferentes dimensões, vai sedimentando-o como um dos seus signos, pode ser de grande valia nesse processo, na medida em que ajuda a perceber as diferentes formas de testemunho nele presentes. Será sobre esses diferentes "níveis testemunhais" que nos deteremos a seguir, pensando-os, sobretudo, na sua relação com a educação enquanto fenômeno histórico.

\section{Os testemunhos do Arquivo sobre a educação}

Desde o século 18, no ocidente, os Estados Nacionais têm procurado, com relativo êxito, implementar a educação escolar, seja assumindo a tarefa de abrir e manter escolas ou, ao menos, supervisionando a iniciativa privada quando esta se une a ele na tarefa de produzir a escolarização. No Brasil, embora as reformas pombalinas tenham dado decisiva contribuição para que se desencadeasse esse movimento (FONSECA, 2011), é bastante evidente na historiografia que foi no século 19 que a oferta da escola tornou-se mais intensa entre nós. (GOUVÊA, 2008). Chegado o final século 20, após muita tensão e negociação, tal processo pode se considerar quase acabado, com a expansão da escolarização à quase totalidade da população infantil brasileira, apesar das grandes desigualdades no que diz respeito ao acesso, permanência e sucesso escolar. (FREITAS; BICCAS, 2009).

Ora, todo esse esforço por fabricar a escola e a escolarização não poderia cair no esquecimento, motivo pelo qual, ainda hoje, encontram-se tantas e tão fartas informações nos arquivos estatais ou institucionais sobre essa história entre nós. Assim, um primeiro nível testemunhal presente nos arquivos é o que podemos chamar de testemunho intencional sobre a educação. Mas, o que significa dizer que este oferece um testemunho 
intencional ao historiador da educação?

Significa reconhecer que ele, deliberadamente, procura evidenciar para a posteridade os compromissos e realizações efetivadas pelo Estado ou por determinadas instituições a ele articuladas no sentido de executar a oferta da escola. Tanto num como noutro caso, trata-se de demonstrar, por diferentes formas, o compromisso nacional (do Estado e demais colaboradores institucionais) com aquela que, tanto no passado como no presente, tem sido alçada a condição, problema e solução para os dilemas de um país. É essa dimensão, inclusive, que torna 0 arquivo e seu testemunho um mecanismo de configuração da memória nacional, tal qual a define Ulpiano Meneses:

a memória nacional, que não é a somatória das diferentes memórias coletivas de uma nação, apresenta-se como unificada e integradora, procurando a harmonia e escamoteando ou sublimando o conflito: é da ordem da ideologia. Por isso mesmo, o Estado e as camadas dominantes - mas nem sempre - são como interessados na reprodução da ordem social (a que ela induz e simbolicamente realiza) os principais responsáveis por sua constituição e circulação. (MENESES, 1992, p. 15).

A natureza intencional desse testemunho do arquivo se manifesta, inclusive, no modo como se estabelecem alguns dos seus fundos documentais, dominados, muitas vezes, por coleções de relatórios, textos legais e impressos oficiais. Dispostos geralmente em ordem cronológica (de acordo com determinadas regras arquivísticas que procuram respeitar a lógica de produção da documentação que, nada mais é que um vestígio da lógica administrativa/institucional que imprimiu tinta em papel) sugerem, per si, ainda que permeados de eventuais lacunas, a própria sequência dos fatos de que querem dar o testemunho e comprovação. Numa paisagem da história assim desenhada pelo desfilar das caixas do arquivo ou de uma coleção de impressos, percebem-se na superfície as maiores ou menores realizações educacionais de um governo, um partido, um período histórico e assim por diante.

Por outro lado, afirmar que o arquivo oferece um testemunho intencional ao trabalho do historiador implica reconhecer que, por conta dessa vontade de lembrar e fazer lembrar o engajamento do Estado e das instituições com a causa nacional da educação, o arquivo é pensado como forma de direcionar o historiador (e a sociedade) a perceber, tão somente, um lado da História da nação e sua educação. É o que nos vêm alertar Carlos Aguirre e Javier Villa-Flores acerca dessa marcante característica, em especial, do patrimônio arquivístico da América Latina, quando escrevem que

longe de serem depósitos imparciais, os arquivos operam a partir de relações de autoridade e força que determinam o que é "arquivável" e o que é "acessível". A sua própria criação, conteúdo e funcionamento são o resultado de ações deliberadas de inclusão e exclusão tendentes a "organizar", "ordenar" e, por isso mesmo, "construir" o passado. (AGUIRRE; VILLA-FLORES, 2009, p. 5, tradução livre).

Assim, sem esconder dos historiadores e demais consulentes um passado arredio às tentativas de produção da escola e da escolarização - os arquivos, por sinal, estão cheios de documentos relatando as dificuldades e, por vezes, fracassos do Estado e seus agentes na marcha da "civilização" e do "progresso" do qual a escola tornou-se, entre nós, bandeira e cavalo de batalha - o arquivo se esforça por ser, pelo que não fala conquanto materializa, um registro social de que, se houve insucesso em algum momento, ele não pode ser atribuído aos grupos dos quais custodia a documentação, mas à realidade rebelde 
nem sempre pronta a acolher e deixar-se transformar por essa instituição da modernidade que é, sobretudo na retórica política, a escola. Claro, não qualquer escola, mas a escola popular estatal ou privada, sob a vigilância atenta daquele que é o vetor das relações sociais de determinada sociedade.

Entretanto, apesar de todos os esforços por esquecer as outras dimensões contrárias à memória social e nacional que ele quer materializar, vestígios e fragmentos dos outros passados que não era sua intenção dar a ver, continuam lá, presentes, prestes a emergir, se, com alguma habilidade, o historiador se prestar a interrogar o Arquivo de outros modos e maneiras. Isso porque, como explica-nos Cláudia Alves:

Se os grupos dominantes têm, em princípio, a posição que mais favorece a instalação de um aparato próprio de memória - desde a solidez de sua moradia até a oportunidade de possuir historiadores a seu serviço - nem por isso terão assegurada sua imunidade ao esquecimento. As épocas subsequentes continuarão tomando parte no processo de seleção, ora ocultando, ora resgatando parcelas de memória de seus antepassados. (ALVES, 2001, p. 21).

E nesse ponto que se apresenta ao historiador um segundo nível de testemunho dos arquivos: o testemunho não intencional sobre a educação. Se a escola é a instituição privilegiada, na maior parte do tempo, como a instância educativa que melhor se adapta às necessidades de "produção da sociedade" (PETITAT, 1994), ela não é a única. Como tem lembrado Luciano Mendes de Faria Filho (2008), no processo de afirmação da forma escolar, outras agências como a Igreja e a Família precisaram ser deslocadas e descentradas, para dar lugar ao novo modo de educar. Pode-se afirmar que elas e suas práticas educativas são a causa de parte significativa dos percalços enfrentados pelo Estado e seus agentes na produção da educação formal em nosso país. Outrossim, a resistência dos sujeitos na sua adesão à implantação dessa forma escolar mesmo dentro da sala de aula - professores, inspetores, alunos - impôs limites à institucionalização da escola e da escolarização, quando não, levou até mesmo ao redirecionamento de algumas das suas facetas entre nós. Mas, como capturar essas e outras vozes discordantes que, por essa razão, destoam e desafinam a sinfonia da memória oficial que o arquivo visa testemunhar?

Antes de tudo, há que se refinar o olhar sobre a documentação e aprender a apreciá-la - sejam os documentos higienizados de uma caixa de arquivo ou as páginas amareladas das obras raras - com certa dose de imaginação histórica, como faz Natalie Zemon Davis quando escreve que

[...] as fontes diretas ou indiretas não são uma prisão. São um fio mágico que me leva a pessoas que morreram a muito tempo, a situações já desaparecidas. Desencadeiam minha reflexão e minha imaginação, dialogo com elas - e o faço com gosto - esta conexão com o passado está no centro de minha vocação de historiadora. (DAVIS, 2006, p. 31, tradução livre).

A meu ver, essa imaginação histórica de que fala a historiadora norte-americana consiste em ter presente que os documentos do arquivo nada mais são que uma porta de entrada à vida e as experiências que realmente importa ao historiador enxergar e elucidar. Adotando as perspectivas do paradigma indiciário (GINZBURG, 1989), eles são como que uma superfície na qual os personagens do passado deixaram alguns rastros, rastros que, devidamente relacionados entre si, meio que formando uma linha pontilhada a ser ligada 
pela interpretação histórica, permitem reconstituir as vozes daqueles que, em princípio, a memória estatal ou institucional tentou varrer ou silenciar nos arquivos. Vozes que ajudam a aproximar-nos de ideias, pensamentos e atitudes que são bastante reveladores da educação na história, mas também da diversidade, pluralidade e contraditoriedade que a atravessa, de resto, como aos demais fenômenos humanos. Essas vozes, uma vez observadas e levadas à tona pelo historiador, não desfazem o arquivo; apenas contornam a memória que o produziu e o transformam, efetivamente, em material histórico.

Uma vez utilizada a imaginação que nos faz reencontrar a vida em meio aos documentos do Arquivo, cabe ponderar, ainda, as crises em torno da relação educação/Estado/Instituições que ele pode acabar vindo a revelar. Crises, como pondera Emília Viotti da Costa,

são momentos de verdade. Elas trazem à luz conflitos que na vida diária permanecem ocultos sobre as regras e rotinas do protocolo social, por trás de gestos que as pessoas fazem automaticamente, sem pensar em seus significados e finalidades. Nesses momentos expõem-se as contradições existentes por trás da retórica e da hegemonia, consenso e harmonia social. (COSTA, 1998, p. 14).

De que crises podem nos falar os arquivos? Penso que neles e nos seus documentos, há vestígios de crises de ordem interna e externa. As crises de ordem interna devem ser buscadas nas incongruências dos próprios sujeitos do aparelho estatal, tanto as declaradas como as, aparentemente, silenciadas. Afinal, apesar de o Estado ser visto como entidade coletiva, ele é composto por pessoas de carne e osso e que em suas individualidades, muitas vezes, não conseguem concordar entre si sobre aquilo que seria o mais adequado para a organização da escola e da escolarização, em determinado momento histórico. Elencar alguns atores ou autores que mais aparecem, persegui-los pelo fio no nome (GINZBURG, 1991) e das suas ideias e posições nas caixas de arquivos ou estantes de obras raras, pode ser um caminho interessante através do qual o historiador vai recuperando parte do material humano de que também se fazem as crises: as relações de poder e força dentro da própria instituição de poder e força que é o Estado.

Todavia, os arquivos também nos dão acesso a crises de ordem externa. Nesse sentido, pode ser de grande valia identificar, num conjunto de documentos ou de uma coleção de obras raras, quais as resistências cotidianas mais comuns à ação escolarizadora do Estado: famílias que não enviam os filhos à escola, professores que não acatam determinadas regras ou tentam subvertê-las em "proveito próprio"; instituições que criticam determinadas atitudes políticas em torno da educação, e assim por diante. Identificadas esses pontos de crise, convém observar os diferentes registros com que aparecem e os diferentes sujeitos que as dão a ver na documentação. Esse exercício certamente começará a apontar outras lógicas e perspectivas, que, devidamente perseguidas, não só podem ajudar na desconstrução da memória oficial sobre a qual se erige 0 arquivo como, sobretudo, a apontar para a necessidade de outras narrativas históricas. Esse, por sinal, é o último ponto sobre o qual o testemunho não intencional do arquivo para a história da educação precisa incidir. É o que ponderam, de novo, Carlos Aguirre e Javier Villa-Flores, já que

[...] o arquivo cumpre também a função de "legitimar" certas maneiras de fazer história e outorgar "autoridade" e "credibilidade" a determinadas fontes, leituras e narrativas. Nenhum arquivo é inocente ou neutro. Desmontar as lógicas existentes 
por trás de sua criação, organização e funcionamento nos permitirá, por sua vez, questionar nosso próprio trabalho como historiadores. Pensar os arquivos é uma maneira de repensar a prática historiográfica e suas conexões com as redes de poder e conhecimento no interior das quais operam os historiadores. (AGUIRRE; VILLA-FLORES, 2009, p. 17, tradução livre).

Em outras palavras: que histórias da educação o testemunho não intencional dos arquivos pode nos levar a escrever? Ao que parece, histórias de como homens, mulheres e crianças se aproximam ou distanciam-se de determinados modelos educativos, ora aceitando-os, ora rejeitando-os, ora produzindo outras significações, apropriando-se a seu modo daquilo que, em princípio, o testemunho intencional do arquivo levava a crer ser apenas e tão somente o modelo de escola/educação do Estado e suas instituições, que valoriza ou coloca em descrédito (para afirmar-se) determinadas formas de educar. Mas, para além disso, o testemunho não intencional sobre o arquivo carrega consigo a possibilidade de levar a própria historiografia a seguir rumos outros, seja reafirmando, sob outras perspectivas, modelos e categorias explicativas já construídas ou desconstruindoas e apresentando novos passados, recompostos com a matéria prima que habita nas caixas dos arquivos.

\section{A título de conclusão}

A reflexão efetuada ao longo deste artigo procurou evidenciar o duplo testemunho que, do Arquivo, emerge para o trabalho do historiador da educação.

De uma parte, o testemunho intencional, nascido da vontade de lembrar e/ou esquecer determinadas questões ligadas à educação - o esforço da memória, que, na origem, motiva o surgimento e organização de todo e qualquer acervo documental. Tanto é que se pode afirmar que o primordial testemunho do Arquivo é aquele que, se devidamente observado e perspectivado, nos diz muito sobre as intenções dos seus produtores e sobre determinado nível das experiências históricas ligadas à educação que desejam manifestar e perenizar no tempo. Embora seja importante para o trabalho do historiador, tal testemunho constitui tão somente a superfície empoeirada que as ferramentas adequadas - como aquelas advindas da teorização das relações entre Memória e História - conseguem soprar para longe, a fim de que apareça, então, outro nível testemunhal: o não intencional.

Este segundo nível de testemunho é aquele que, apesar de todo esforço de memória e relações de poder que sobre o Arquivo atuam, continua presente e latente na documentação, desde que, para tanto, o historiador desenvolva junto das ferramentas intelectuais acima mencionadas aquelas de uma certa imaginação histórica e sensibilidade de pesquisa, que o ajudem a reencontrar, nas caixas dos arquivos, as contradições presentes nas experiências que este, mesmo a revelia, permite acessar. Outras vozes e versões de um mesmo passado, que só serão ouvidas, compreendidas e levadas na devida conta pelo ingente esforço do historiador e da historiadora da educação em submeter a memória e suas seduções, ao exercício disciplinado e sistematizado da operação histórica.

Todavia, se, num primeiro momento, pode parecer que é, unicamente, o segundo testemunho $\circ$ mais importante e revelador para 0 trabalho da pesquisa histórico educacional, vale reafirmar que não se chega a ele, sem antes, ouvir e indagar, constantemente, o primeiro tipo de testemunho que o Arquivo, tanto ontem (no momento 
de sua produção) como hoje (no momento de sua inquirição) insiste em dar. No limite, é só da articulação dos dois tipos de testemunhos que o arquivo será explorado em todas as suas possibilidades no trabalho da escrita da História da Educação.

\section{Referências}

AGUIRRE, Carlos; VILLA-FLORES, Javier. Los archivos y la construcción de la verdad histórica en America Latina. Jahrbuch für Geschichte Lateinamerikas - Anuario de Historia de America Latina, Ursulaplatz, n. 46, p. 5-17, 2009.

ALVES, Cláudia Maria Costa. Acervos bibliográficos para a História da Educação. Niterói: EDUFF, 2001.

BASTOS, Maria Helena Câmara. O que é a História da Educação no Brasil hoje? Tempos de reflexão. Espacio, Tiempo y Educación, v. 3, n. 1, p. 43-59, jan./jun. 2016.

BLOCH, Marc. A Apologia da História ou O Ofício do Historiador. Rio de Janeiro: Jorge Zahar, 2011.

BUFFA, Ester. Os 30 anos do GT de História da Educação: sua contribuição para a constituição do campo. Revista Brasileira de História da Educação, Maringá, v. 16, n. 4, p. 393-419, 2016.

BURKE, Peter. História como memória social. In: BURKE, Peter. Variedades de História Cultural. Rio de Janeiro: Civilização Brasileira, 2000. p. 67-90.

CARR, Edward. O que é História? Rio de Janeiro: Paz e Terra, 2006.

CARVALHO, Marta Maria Chagas de. A historiografia da educação no Brasil: tradições historiográficas e reconfiguração de um campo de pesquisa. In: CARVALHO, Marta Maria Chagas de. A Escola e a República e outros ensaios. Bragança Paulista: EDUSF, 2003. p. 281-312.

CARVALHO, Marta Maria Chagas de; NUNES, Clarice. Historiografia da educação e fontes. Cadernos ANPEd, Porto Alegre, n. 5, p. 7-64, 1993.

CATANI, Denice Bárbara; FARIA FILHO, Luciano Mendes de. Um lugar de produção e a produção de um lugar: a história e a historiografia divulgadas no GT História da Educação da ANPEd (1985-2000). Revista Brasileira de Educação, Campinas, n. 19, p. 114-128, jan./abr. 2002.

CERTEAU, Michel de. A Escrita da História. Rio de Janeiro: Forense Universitária, 2002.

COSTA, Emília Viotti da. Coroas de glória, lágrimas de sangue: a rebelião dos escravos de Demerara em 1823. São Paulo: Companhia das Letras, 1998.

CUNHA, Maria Teresa Santos. Essas coisas de guardar... homens de letras e acervos pessoais. História da Educação, Pelotas, v. 12, p. 109-130, 2008.

DAVIS, Natalie Zemon. Pasión por la Historia: entrevista com Denis Crouzet. Valência: PUV, 2006.

DUBY, Georges. Escribir la Historia. Reflexiones, Costa Rica, v. 25, n. 1, p. 1-9, 1994.

FARGE, Arlette. O Sabor do Arquivo. São Paulo: Edusp, 2009.

FARIA FILHO, Luciano Mendes de. O processo de escolarização em Minas Gerais: questões teórico-metodológicas e perspectivas de pesquisa. In: VEIGA, Cynthia Greive; LIMA, Thaís Nívia Fonseca de. História e historiografia da educação no Brasil. Belo Horizonte: Autêntica, 2008. p. 77-98.

FARIA FILHO, Luciano Mendes de; VIDAL, Diana Gonçalves. As lentes da História: 
estudos de História e Historiografia da Educação no Brasil. Campinas: Autores Associados, 2005.

FEBVRE, Lucien. Combates pela História. Lisboa: Presença, 1989.

FONSECA, Thaís Nívia de Lima. As Reformas Pombalinas no Brasil. Belo Horizonte: Mazza Edições, 2011.

FRANÇOIS, Etienne. Os "Tesouros da Stasi" ou a Miragem dos Arquivos. In: BOUTIER, Jean; JULIA, Dominique (Orgs.). Passados recompostos: campos e canteiros da História. Rio de Janeiro: Editora da FGV, 1998. p. 155-162.

FREITAS, Marcos Cezar; BICCAS, Maurilane de Souza. História social da educação no Brasil: 1926-1996. São Paulo: Cortez, 2009.

GINZBURG, Carlo. O nome o como: troca desigual e mercado historiográfico. In:

GINZBURG, Carlo. A micro-história e outros ensaios. Lisboa: Difel, 1991. p. 169-178.

GOUVÊA, Maria Cristina Soares de. A escolarização da criança brasileira no século 19: apontamentos para uma reescrita. Educação em Questão, Natal, v. 28, n. 14, p. 121 146, jan./jun. 2007.

HALBWACHS, Maurice. A memória coletiva. São Paulo: Centauro, 2006.

HILSDORF, Maria Lúcia. A série ofícios diversos do Arquivo do Estado de São Paulo como fonte para a história da educação brasileira. In: VIDAL, Diana Gonçalves; SOUZA, Maria Cecília Cortez de (Orgs.). A memória e a sombra: a escola brasileira entre 0 Império e a República. Belo Horizonte: Autêntica, 1999. p. 13-19.

HOBSBAWM, Eric. A Era das Revoluções 1789-1848. Rio de Janeiro: Paz e Terra, 2015.

HOBSBAWM, Eric; RANGER, Terence (Orgs.). A invenção das tradições. Rio de Janeiro: Paz e Terra, 1988.

JANSSENS, Gustaaf. Los lugares de la memoria archivistica europea: un reconocimiento del recorrido. Pliegos de Yuste, Cuácos de Yuste, n. 11-12, p. 83-90, 2010.

LE GOFF, Jacques. História e Memória. Campinas: Editora da Unicamp, 1990.

LOPES, Eliane Marta Santos; GALVÃO, Ana Maria de Oliveira. Território Plural: a pesquisa em História da Educação. São Paulo: Ática, 2010.

MARTINS, Maria do Carmo; ROCHA, Heloísa Helena Pimenta da. Lugares de memória: sedução, armadilhas, esquecimento e incômodos. Horizontes, 23 (2), p. 91-99, jul./dez. 2005.

MENESES, Ulpiano Bezerra de. A História cativa da memória? Para um mapeamento da memória no campo das ciências sociais. Revista do Instituto de Estudos Brasileiros, São Paulo, n. 34, p. 9-34, 1992.

MOGARRO, Maria João. Os arquivos escolares nas instituições educativas portuguesas. Preservar a informação, construir a memória. Pro-posições, Campinas, v. 16, n. 1, p. 103-116, jan./abr. 2005.

NORA, Pierre. Entre Memória e História: a problemática dos lugares. Projeto História. São Paulo, v. 10, p. 7-28, 1993.

NUNES, Clarice. História da educação: espaço do desejo. Em Aberto, Brasília, n. 47, p. 37-46, jul./set. 1990.

PERROT, Michelle. Introdução. In: PERROT, Michelle. As mulheres ou os silêncios da História. Bauru: Edusc, 2005. p. 9-30. 
PETITAT, André. Produção da escola, produção da sociedade. Porto Alegre: Artes Médicas, 1994.

SALOMON, Marlon. Saber dos arquivos. In: SALOMON, Marlon (Org.). Saber dos Arquivos. Goiânia: Edições Ricochete, 2011. p. 5-18.

SALVADORI, Maria Ângela Borges; BICCAS, Maurilane de Souza. Editorial do dossiê História, Historiografia e Ideias Educacionais. Horizontes, Bragança Paulista, v. 23, n. 2, p. 89-90, jul./dez. 2005.

THOMPSON, Edward. A miséria da teoria ou um planetário de erros. Curitiba: Copyflex, 2009.

VEIGA, Cynthia Greive. História da Educação. São Paulo: Ática, 2007.

JUAREZ JOSÉ TUCHINSKI DOS ANJOS é professor adjunto da Faculdade de Educação na Universidade de Brasília (UnB). Doutor em Educação pela Universidade Federal do Paraná (UFPR). Desenvolve, principalmente, pesquisas na área de história da educação no século XIX, privilegiando os temas ligados à história da escolarização, história da infância e história da educação da criança pela família.

Endereço: SQN 214, Bloco D - ap. 213, 70873-040, Asa Norte, Brasília/DF, Brasil.

E-mail: juarezdosanjos@yahoo.com.br

Recebido em 17 de julho de 2017.

Aceito em 22 de setembro de 2017. 